\title{
Technology Development for the Construction of ITER Superconducting Magnet System
}

\author{
K. Okuno, H. Nakajima, M. Sugimoto, T. Isono, K. Kawano, N. Koizumi, K. Hamada, \\ Y. Nunoya, Y. Nabara, K. Kitamura, M. Oshikiri, K. Takano, F. Tsutsumi \\ Japan Atomic Energy Agency (JAEA), Naka-shi, Ibaraki-ken, Japan \\ e-mail contact of main author: okuno.kiyoshi@jaea.go.jp
}

\begin{abstract}
Japanese contribution to the construction of the ITER superconducting magnet system is to procure $25 \%$ of TF conductors, about half of TF coil winding packs, all of TF coil structures and all of CS conductors. JAEA has started extensive technology development for the preparation of these procurements. These include (1) trial fabrication of the superconductors at industry level and their performance demonstration, (2) manufacturing studies on the TF coil winding pack and structures, (3) full-scale trial fabrication of TF coil structures, and (4) establishment of database on the structural materials. All of these activities are performed in tight collaboration with Japanese industry involving around 20 major companies. Up to date, advanced $\mathrm{Nb}_{3} \mathrm{Sn}$ strands have been developed, manufacturing studies on the TF coil winding and structures have been performed, and trial manufacture of structural materials at full scale has been performed. All of these results are satisfactory, although further technology development is required in some areas, including the qualification of conductors and establishment of welding procedures of structures.
\end{abstract}

\section{Introduction}

The ITER superconducting magnet system consists of 18 Toroidal Field (TF) coils, one Central Solenoid (CS) and six Poloidal Field (PF) coils. The TF coils have a D-shape with a height of $14 \mathrm{~m}$ and a width of $9 \mathrm{~m}$. The CS is composed of six identical modules, which are stacked into an assembly of $12 \mathrm{~m}$ height and supported by a pre-compression structure. The PF coils are ring coils located at the outside of the TF coils and the largest PF coil has an outer diameter of $25 \mathrm{~m}$. Maximum fields are $11.8 \mathrm{~T}$ in the TF coil, $13 \mathrm{~T}$ in the $\mathrm{CS}$, and below $6 \mathrm{~T}$ in the PF coils. The CS and TF coils use $\mathrm{Nb}_{3} \mathrm{Sn}$ superconductor and PF coils use NbTi conductor. In 2005, Cadarache was selected as ITER site by the six Participant Teams (PTs), namely, Japan, China, EU, Korea, Russia and US, and India newly joined ITER. All PTs except for India will make contributions to the procurement of the magnet system. Among six PTs, Japan, EU and US are responsible for major part of the superconducting magnets. Japan Atomic Energy Agency (JAEA) has therefore started preparation activities for the magnet procurement, as described in this paper.

\section{Procurement Preparation of the ITER Magnet System in Japan}

In the procurement of the magnet system, Japanese contribution is the largest among PTs, including the following four areas: 1) $25 \%$ of TF conductors, 2) about half ( 9 out of 19) of TF coil winding packs, 3) all of TF coil structures and 4) all of CS conductors. FIG. 1 shows Japanese contributions to the TF coil manufacturing. The amount of $\mathrm{Nb}_{3} \mathrm{Sn}$ strands to be produced in Japan corresponds to approximately 100 tons for TF conductor and 120 tons for CS conductor. The amount of stainless steels to be used in 19 TF coils is 3,800 tons for coil cases and 1,100 tons for radial plates. To fabricate these structures, ingots of more than 10,000 tons have to be produced as raw materials. Regarding the schedule, the ITER project assumes about two years for regulatory process and eight years for the construction until the first plasma is obtained. The last part of the construction period of about two years is for tokamak assembly at site. Therefore, magnets have to be manufactured within six years or so. In order to meet this schedule requirement, efficient and rational manufacturing scheme has to be 


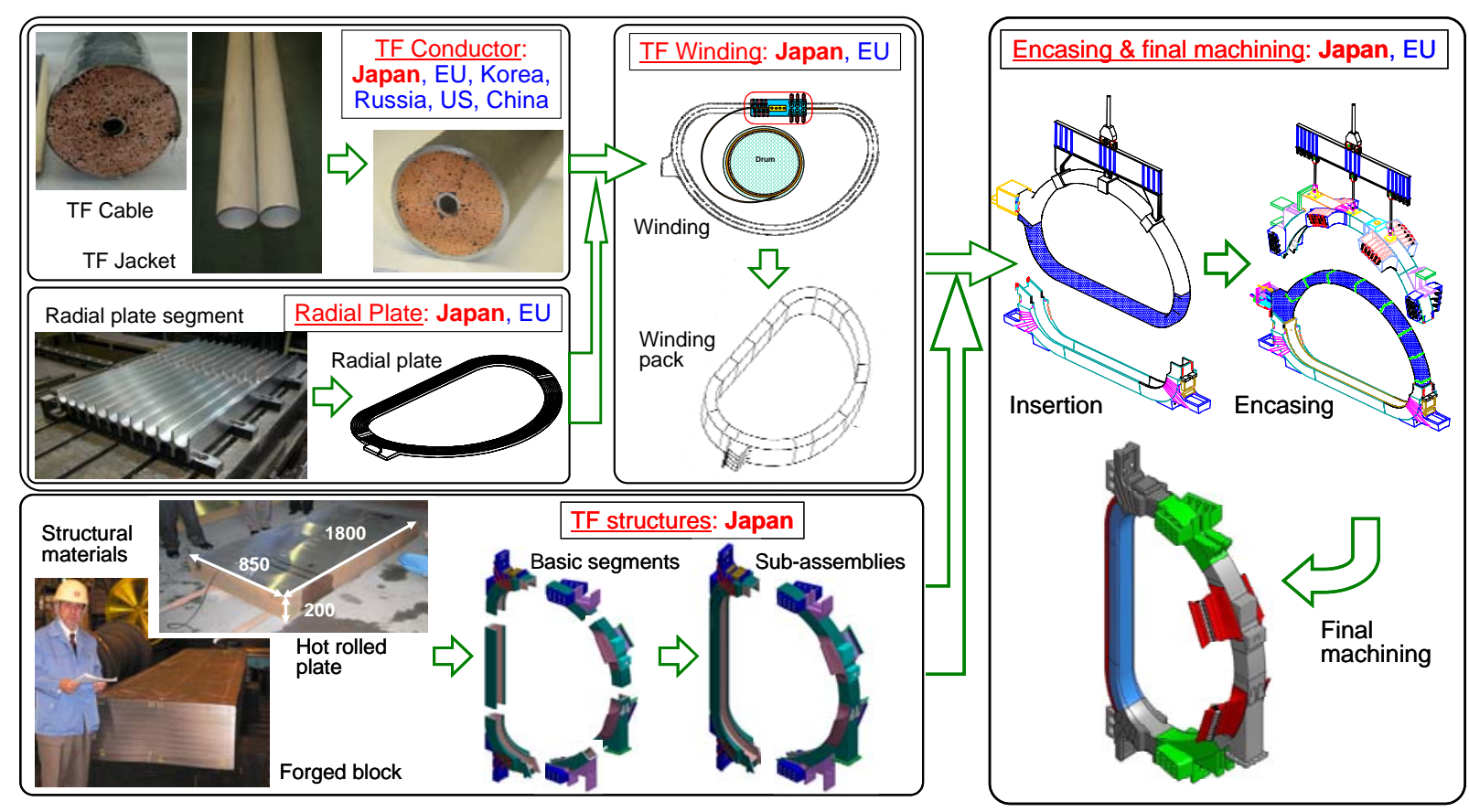

FIG. 1. Japanese contributions to the TF coil manufacturing.

established and multiple suppliers have also to be qualified for critical components, such as $\mathrm{Nb}_{3} \mathrm{Sn}$ strands and structural materials. In addition, magnet procurement scenario does not close inside a single PT ("commingling"). For example, TF conductors will be produced in the six PTs, which will then be transferred to JA and EU for winding. This scheme complicates the control of schedule and quality assurance (QA), and creates interface issues. Considering these conditions, JAEA has started extensive activities on the procurement preparation of superconducting magnet in tight collaboration with Japanese industry involving around 20 major companies [1]. JAEA is responsible for performing R\&Ds and organizing optimum structures for the procurement with detailed definition of interface conditions.

\section{Conductor}

\section{1. $\mathrm{Nb}_{3} \mathrm{Sn}$ Strand Development}

In the CS model coil projects [2], JAEA have developed two types of $\mathrm{Nb}_{3} \mathrm{Sn}$ strands, bronze process and internal tin process strands. However, the results of the model coil experiments have revealed a significant loss of superconducting performance in a cable-in-conduit conductor under a large transverse electromagnetic load [3]. In order to compensate this loss, new requirements have been specified for ITER $\mathrm{Nb}_{3} \mathrm{Sn}$ strands with an increase in critical current density $\left(\mathrm{J}_{\mathrm{c}}\right)$ and mitigation in hysteresis loss $\left(\mathrm{Q}_{\mathrm{h}}\right)$, as shown in Table I, taking into account recent progress in $\mathrm{Nb}_{3} \mathrm{Sn}$ strand technology triggered by ITER.

TABLE I: STRAND SPECIFICATIONS.

\begin{tabular}{|c|c|c|c|c|c|c|}
\hline \multirow{3}{*}{ Strand type } & \multirow{2}{*}{\multicolumn{2}{|c|}{ CS Model Coil }} & \multicolumn{4}{|c|}{ New ITER specifications } \\
\hline & & & \multicolumn{2}{|c|}{ TF coil } & \multicolumn{2}{|c|}{$\mathrm{CS}$} \\
\hline & $\mathrm{J}_{\mathrm{c}}$ & $\mathrm{Q}_{\mathrm{h}}$ & $\mathrm{J}_{\mathrm{c}}$ & $\mathrm{Q}_{\mathrm{h}}$ & $\mathrm{J}_{\mathrm{c}}$ & $\mathrm{Q}_{\mathrm{h}}$ \\
\hline Internal tin & $>650$ & $<600$ & $>800$ & \multirow{2}{*}{$<1,000$} & $>950$ & \multirow{2}{*}{$<1,000$} \\
\hline Bronze & $>550$ & $<200$ & $>700$ & & $>750$ & \\
\hline
\end{tabular}




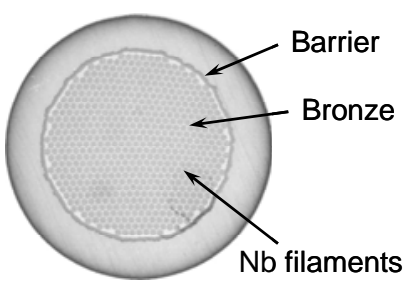

(a) Bronze process strand

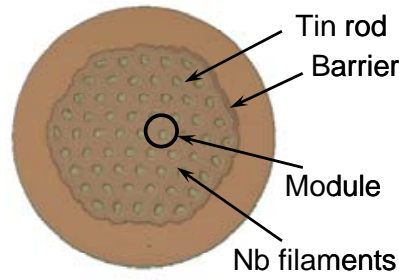

(b) Internal tin process strand

FIG. 2. $\mathrm{Nb}_{3}$ Sn strands (0.82 $\mathrm{mm} \mathrm{dia)}$.

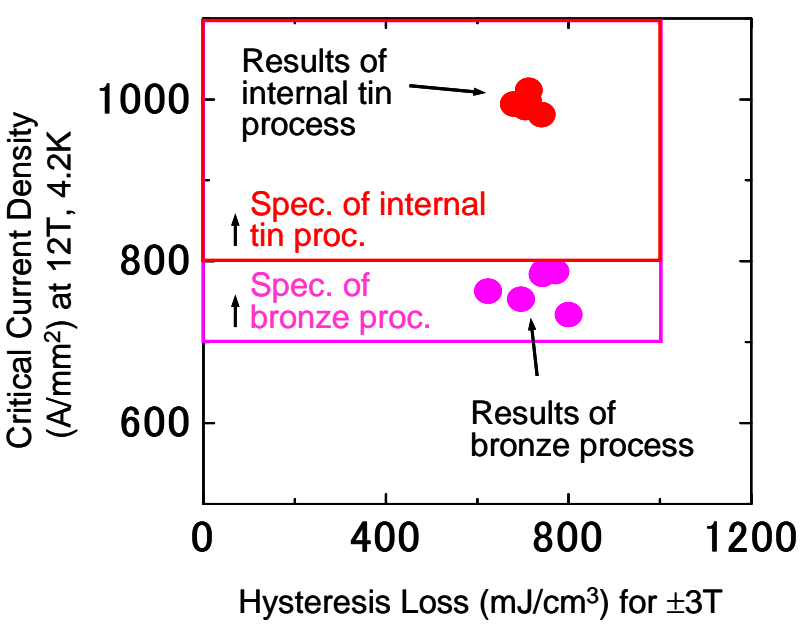

FIG. 3. Critical current density and hysteresis loss of newly-developed strands.

In addition, the amount of strands required for the ITER magnets is significantly larger than that in the CS model coils (25 tons in total). An increase in the number of strand supplies was desired. A trial fabrication, together with the qualification of suppliers, was therefore started. This trial involved four suppliers in Japan and around 15 suppliers in the six PTs. About 0.1 ton of $\mathrm{Nb}_{3} \mathrm{Sn}$ strands were produced at each supplier using full size billets in order to demonstrate mass production capability. In Japan, the trial was performed as follows. In the bronze process strands, bronze with high Sn content of 15 to $16 \%$ became available, which enabled $J_{c}$ to increase. In addition, owing to the mitigation of $\mathrm{Q}_{\mathrm{h}}$, a use of $\mathrm{Nb}$ barrier instead of Ta became possible, resulting in an improvement of productivity. In internal tin process strands, the size of modules, each of which consists of a tin rod and a lot of $\mathrm{Nb}$ filaments embedded in a copper cylinder, was optimized to increase the total amount of Sn while maintaining $\mathrm{Q}_{\mathrm{h}}$ at reasonably low level. FIG. 2 shows cross sectional views of $\mathrm{Nb}_{3} \mathrm{Sn}$ strands. As shown in FIG. 3, typical $J_{c}$ of $1,000 \mathrm{~A} / \mathrm{mm}^{2}$ and $Q_{h}$ of $700 \mathrm{~mJ} / \mathrm{cm}^{3}$ were obtained in the internal tin process strands, and $J_{c}$ of $750 \mathrm{~A} / \mathrm{mm}^{2}$ and $Q_{h}$ of $700 \mathrm{~mJ} / \mathrm{cm}^{3}$ were obtained in the bronze process strands. These performances satisfy the ITER requirements.

\section{2. $\mathrm{Nb}_{3} \mathrm{Sn}$ Strand Characterization}

A $\mathrm{Nb}_{3} \mathrm{Sn}$ strand is very susceptible to an external strain and superconducting performances such as critical current density, critical temperature and critical field, can easily be degraded. It is therefore very important to evaluate $\mathrm{Nb}_{3} \mathrm{Sn}$ strand performances under strain applied conditions to confirm the ITER conductor design. JAEA has newly developed an apparatus to impose a strain on a strand and measure its critical current $\left(I_{c}\right)$. The measurements can be performed under the magnetic field up to $15 \mathrm{~T}$, temperature range of $4.2 \mathrm{~K}$ to $15 \mathrm{~K}$ and strain range of $-0.8 \%$ (compressive) to $0.5 \%$ (tensile) [4]. FIG. 4 shows an example of measured $\mathrm{I}_{\mathrm{c}}$-strain relation at $12 \mathrm{~T}$ for the

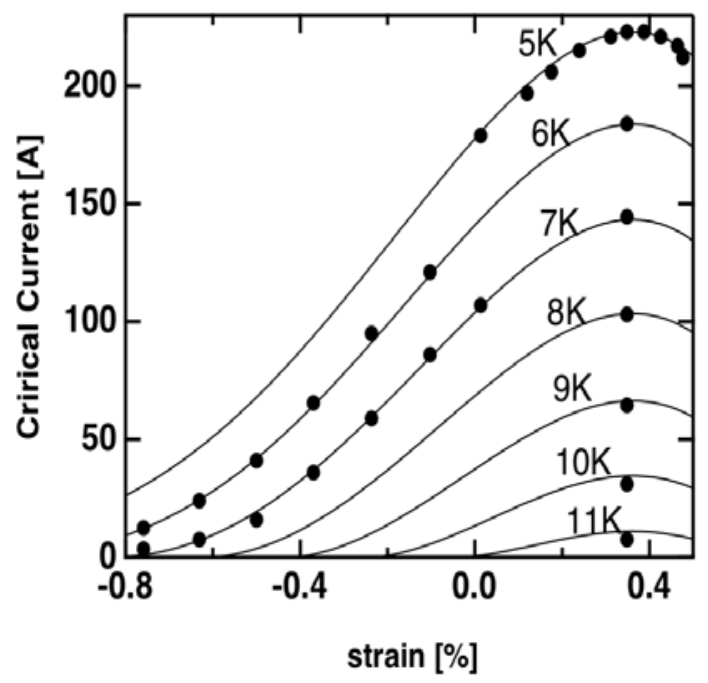

FIG. 4. $I_{C}$-strain relation at $12 \mathrm{~T}$. 
bronze strand. From this figure, upper critical field, $\mathrm{B}_{\mathrm{c} 2}(0)=29.83 \mathrm{~T}$ and critical temperature $\mathrm{T}_{\mathrm{c}}=17.13 \mathrm{~K}$ can be derived [4]. These values support the design basis of the ITER conductor. This characterization will be performed on strands from all different suppliers.

\subsection{Cable Development}

The manufacturing method of a superconducting cable was successfully established in the CS model coil project. To enhance total critical current of the conductor, however, a different configuration of the cable was proposed for the TF coil conductor. This includes reductions in a void fraction at cable space and cross-sectional area of a central cooling channel from those of the CS model coil conductor. These changes make cable fabrication difficult because large compaction of six sub-cables is required to achieve a specified diameter. A trial fabrication of the TF cable was therefore performed. A full scale TF cable consisting of $900 \mathrm{Nb}_{3} \mathrm{Sn}$ strands and 522 copper wires cabled at five stages of $3 \times 3 \times 5 \times 5 \times 6$ was successfully manufactured, and the specified cable diameter of $41.1 \mathrm{~mm}$ was obtained. A part of the cable was enclosed in a jacket to form a conductor (see FIG. 1). The confirmation of conductor performance will be performed with this conductor using the SULTAN facility in EU in early 2007.

\subsection{Jacket Material Development}

JAEA has been developing jackets for conductors in the cooperation with Japanese steel companies. The TF conductor uses a thin-walled circular jacket made of SS316LN, and the CS conductor uses heavy-walled square jacket made of JK2LB [5]. JAEA has already made TF jackets of about $100 \mathrm{~m}$ in total with a unit length of $14 \mathrm{~m}$.

A jacket material for the CS conductor requires lower thermal expansion from room temperature to $4 \mathrm{~K}$ than that of usual stainless steel $(\Delta \mathrm{L} / \mathrm{L}=0.3 \%)$ in order to obtain sufficient compressive loading to CS winding packs from a preload structure during cool down. To satisfy this requirement, JK2LB $(\Delta \mathrm{L} / \mathrm{L}=0.2 \%)$ developed by JAEA was selected. A trial fabrication of JK2LB jackets was performed to demonstrate fabrication processes. Tensile and fracture toughness tests were then performed using samples cut from the jackets. Cold work was imposed to the samples to simulate processes in conductor fabrication and coil winding. Test results indicated a degradation of the fracture toughness due to the cold work while it enhanced the yield strength. It was therefore necessary to optimize the chemical compositions of JK2LB, especially on nitrogen and carbon, in order to balance between fracture toughness $\left(\mathrm{K}_{\mathrm{IC}}\right.$ ) and $0.2 \%$ yield strength (YS). FIG. 5 shows the results of $0.2 \%$ YS and $\mathrm{K}_{\mathrm{IC}}$ of JK2LB in function of the nitrogen plus carbon content. The figure indicates that the nitrogen plus carbon content has to be less than $0.175 \%$ to satisfy the requirements (YS of more than $900 \mathrm{MPa}$ and $\mathrm{K}_{\mathrm{IC}}$ of more than $130 \mathrm{MPam}^{0.5}$ ). Since carbon content can be kept at less than $0.025 \%$, nitrogen content was decided to be 0.09 to $0.15 \%$. CS jackets with the optimized nitrogen content are under fabrication and their mechanical properties will be confirmed soon.

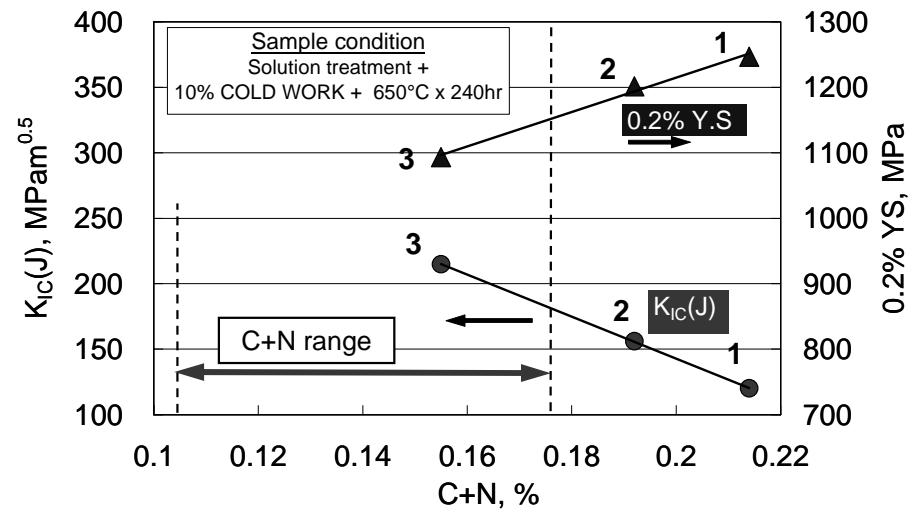

FIG. 5. 0.2 yield strength (YS) and fracture toughness $\left(K_{I C}\right)$ of JK2LB with $10 \%$ cold work. 


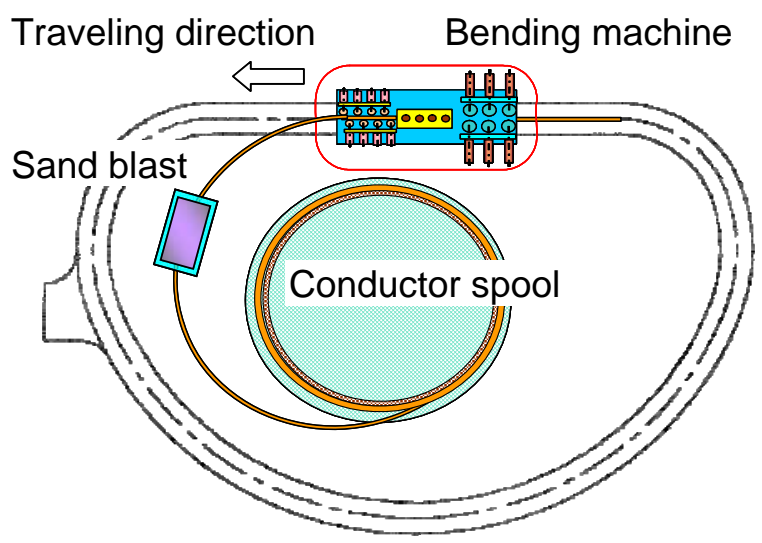

FIG. 6. A concept of winding machine.

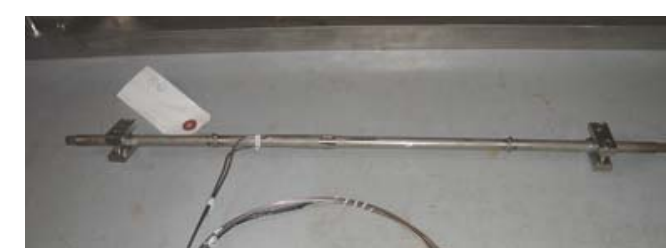

(a) Sub-cable sample (0.4 m long)

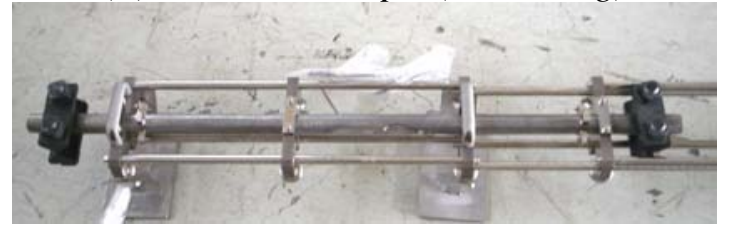

(b) full scale conductor sample (1 $\mathrm{m}$ long)

FIG.7. Samples to measure conductor elongation during heat treatment.

\section{TF Coil}

TF coil manufacturing processes can be divided into three major parts, as already shown in FIG. 1: (1) winding pack manufacture, (2) structure manufacture, and (3) encasing of the winding pack and final machining. The winding pack is composed of seven double pancakes, each of which has a radial plate as a structure. The radial plate has a groove on each side of the surfaces and conductor is inserted into this groove. Before the insertion, the conductor is heat treated for $\mathrm{Nb}_{3} \mathrm{Sn}$ formation at $650^{\circ} \mathrm{C}$ for 200 hours. Seven double pancakes are stacked together and are vacuum pressure impregnated in order to form a rigid winding pack. Regarding the structures, large forged blocks or plates are produced and machined to basic segments, which are then assembled by welding into four large sub-assemblies. At the last stage of the manufacturing, the winding pack is inserted into the sub-assemblies, closure welding is performed, and final machining is performed to obtain specified dimensions and interface conditions.

\subsection{Manufacturing Study of TF Coil Winding}

Manufacturing of TF coil winding requires very large manufacturing tools. One of the critical issues is to realize the precise dimensions of the conductor winding (typical tolerance of $+/-1.5 \mathrm{~mm}$ ) after the heat treatment so that the winding can be inserted into the grooves of a radial plate. Since $\mathrm{Nb}_{3} \mathrm{Sn}$ conductor elongates by 0.1 to $0.2 \%$ due to heat treatment, precise prediction of the change in shape due to the elongation is necessary. FIG. 6 shows a concept of a winding machine, which travels along the circumferential direction. FIG. 7 shows a R\&D activity to establish database on the elongation of the conductor during heat treatment. These will be used for the detailed design of the tools and determination of the winding dimensions.

\subsection{Radial Plate Development}

A radial plate is a $13.7 \mathrm{~m} \times 8.7 \mathrm{~m}$ D-shaped plate having a groove on each surface. ST316LN will be used as a material. Tight requirements on dimensional accuracy are required, for example, flatness of $2 \mathrm{~mm}$ over the entire plate. JAEA has therefore started a full scale demonstration on the radial plates manufacture in collaboration with Japanese industries. In the manufacturing procedures developed so far, seven segments are machined separately using small milling machines and then assembled together by a laser welding machine to form a full radial plate [6]. Trial manufacture of 1-m segments was performed based on these procedures, as shown in FIG. 8. 


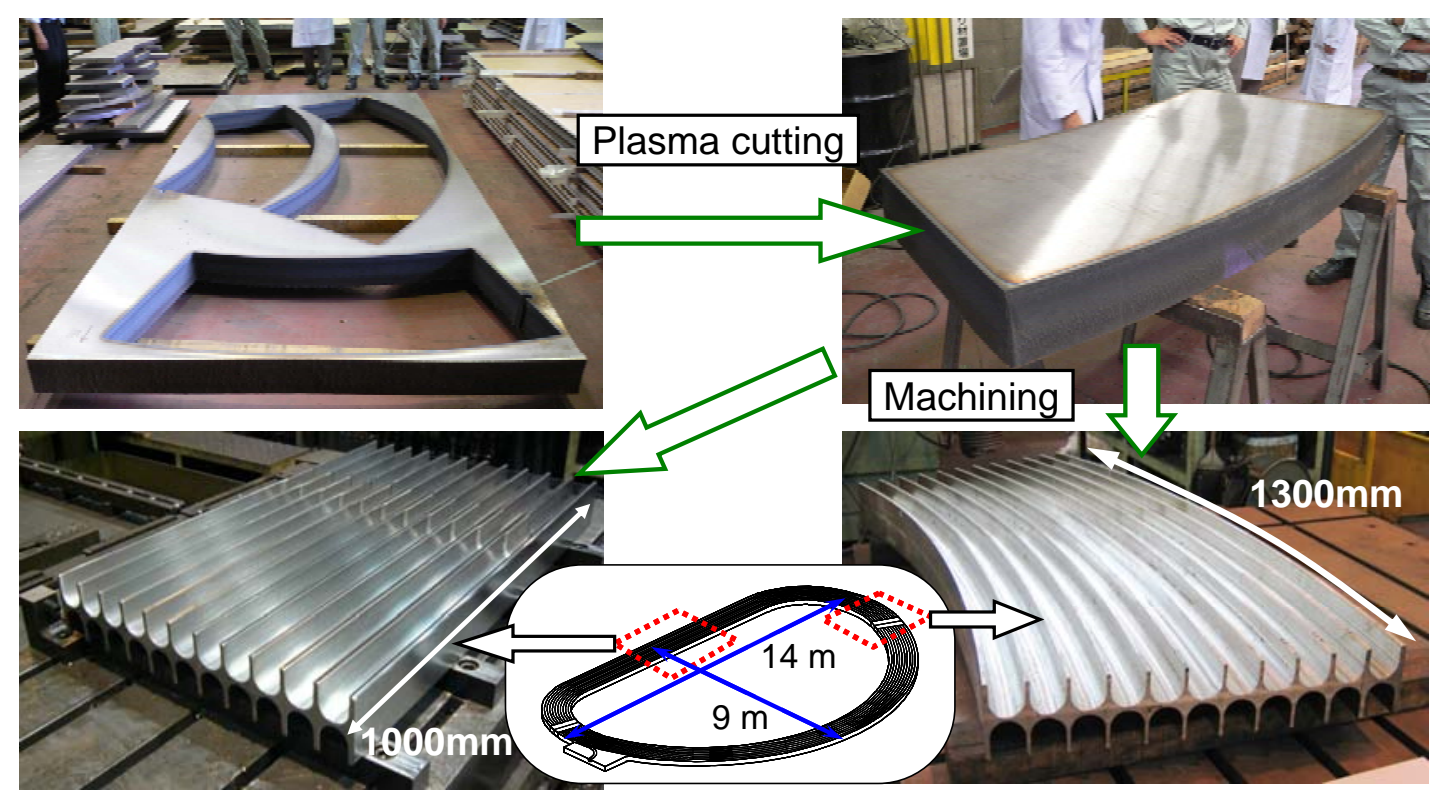

FIG. 8. Fabrication trial of 1-m long straight and curved segments for radial plate.

In the trial, straight and curved segments of the radial plate were cut from hot rolled plates using a plasma cutting method. Machining was then performed to make grooves on both surfaces. One of the objectives in this trial was to identify deformation during groove machining. The curved segment showed a complicated deformation, and a flatness of 4.83 $\mathrm{mm}$ was observed, which is more than 6 times of $0.75 \mathrm{~mm}$ in the straight segment. Detailed investigation indicated that the effect of residual stresses in the hot rolled plate was enhanced by the machining of curved grooves, which caused a large deformation. A measure to mitigate the deformation is initiated by optimizing the grooving direction to be in parallel as much as possible to the hot rolling direction [6].

In order to demonstrate a connection of radial plate segments, two grooved segments were welded together along the radial direction using $4 \mathrm{~kW}$ YAG laser welding machine. A manual TIG welding followed the laser welding to compensate the lack of laser power for full penetration. Further development on higher power laser welding is underway [6].

\subsection{Coil Case Development}

The TF coil case uses several kinds of materials depending on the requirement of the mechanical strength. The maximum thickness of the case is more than $200 \mathrm{~mm}$ and forged blocks and hot rolled plates will be used as a material. At the highest stress area, where yield strength (YS) of more than $1,000 \mathrm{MPa}$ at $4 \mathrm{~K}$ is required, forged JJ1 (12Cr- $12 \mathrm{Ni}-10 \mathrm{Mn}-$ $5 \mathrm{Mo}-0.24 \mathrm{~N}$ ) will be used. At the second highest stress area (YS more than $850 \mathrm{MPa}$.), forged ST316LN (strengthened 316LN with nitrogen content of more than $0.17 \%$ ) will be used. At relatively low stress area (YS more than $650 \mathrm{MPa}$ ), 316LN will be used. Since these structures are quit large in size, fabrication demonstrations of these materials have been performed. FIG. 9 shows the some of the products from the trial fabrication. JJ1 forging (thickness of $370 \mathrm{~mm}$, weight of 11 tons), ST316LN forging (thickness of $400 \mathrm{~mm}$, weight of 26 tons) and two ST316LN hot rolled plates (thickness of $140 \mathrm{~mm}$, weight of 11 tons and thickness of $200 \mathrm{~mm}$, weight of 6 tons) have been manufactured in an actual industrial route. In order to verify the uniformity of the mechanical properties of these materials, mechanical tests were performed, including fatigue characteristics [7]. Test samples were cut from forged blocks and plates at the positions of $0 / 8,1 / 8,1 / 4,3 / 8$ and $1 / 2$ of the thickness at the head and 

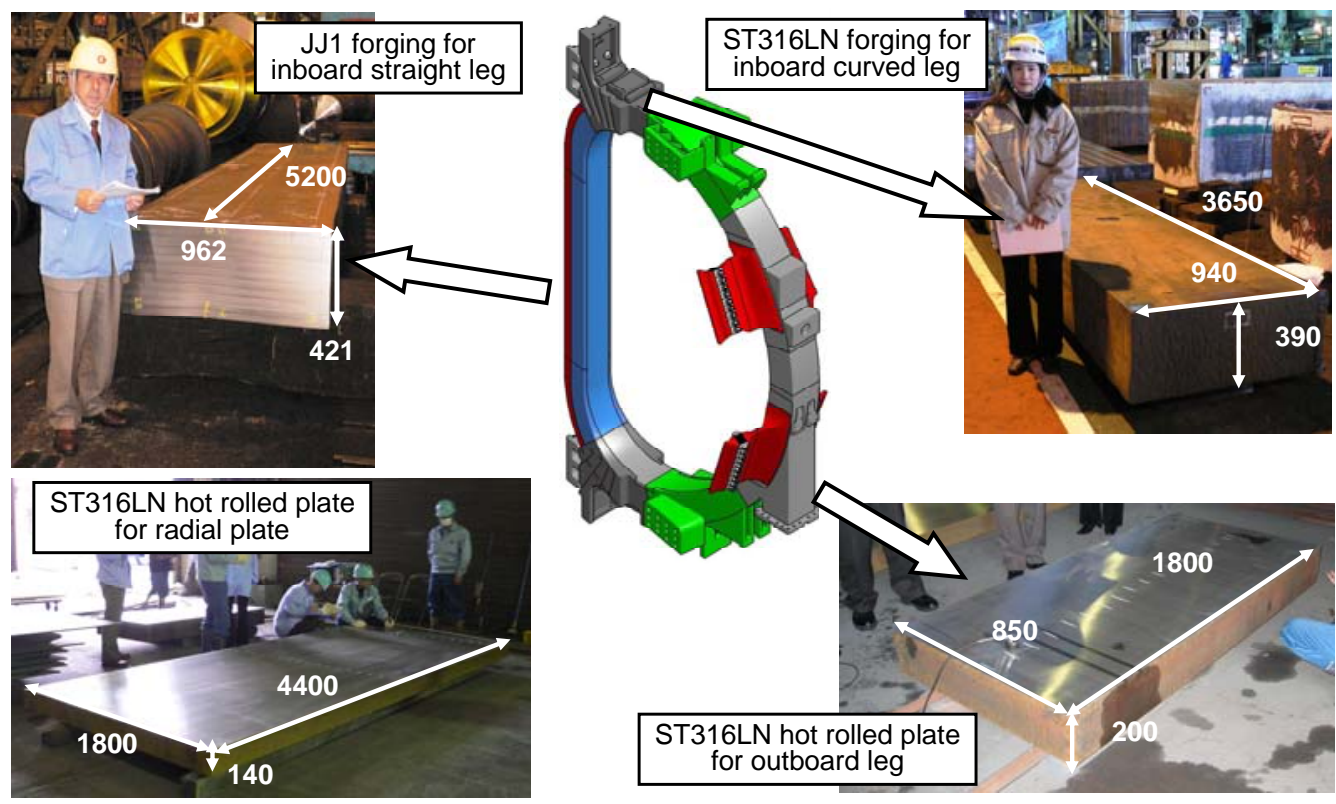

FIG. 9. Trial fabrication of JJ1 forging, ST316LN forging and two ST316LN hot rolled plates.

tail portions. The results of yield strength (YS) and ultimate tensile strength (UTS) at $4.2 \mathrm{~K}$ are summarized in Table II. The average YS of JJ1 forging reached 1,126 MPa, which fairly exceeded the required value. The minimum YS of $987 \mathrm{MPa}$ appeared near the surface of the block. In a practical use, some amount of material will be removed from the surface during machining and this value is not problematic. The average YS of ST316LN forging exceeded the required value of $850 \mathrm{MPa}$, and it reached around 1,078 MPa. In the 200-mm and 140-mm thick hot rolled plates, the minimum values of YS (968 MPa and $989 \mathrm{MPa}$, respectively) appeared at $1 / 8$ of the thickness from the surface, although both satisfied the requirements.

TABLE II: MECHANICAL TEST RESULTS OF STRUCTURAL MATERIALS.

\begin{tabular}{|l|c|c|c|c|c|c|c|c|}
\hline \multirow{2}{*}{} & \multicolumn{2}{|c|}{$\begin{array}{c}\text { JJ1 } \\
\text { forging }\end{array}$} & \multicolumn{2}{c|}{$\begin{array}{c}\text { ST316 } \\
\text { forging }\end{array}$} & \multicolumn{2}{c|}{$\begin{array}{c}\text { ST316 } \\
\text { 200-mmt plate }\end{array}$} & \multicolumn{2}{c|}{$\begin{array}{c}\text { ST316 } \\
\text { 140-mmt plate }\end{array}$} \\
\cline { 2 - 10 } & YS & UTS & YS & UTS & YS & UTS & YS & UTS \\
\hline Average & 1,126 & 1,527 & 1,078 & 1,614 & 1,080 & 1,596 & 1,053 & 1,612 \\
\hline Max. & 1,392 & 1,610 & 1,145 & 1,654 & 1,164 & 1,666 & 1,144 & 1,652 \\
\hline Min. & 987 & 1,478 & 961 & 1,563 & 968 & 1,313 & 989 & 1,496 \\
\hline Spec. & 1,000 & - & 900 & - & 850 & - & 950 & - \\
\hline
\end{tabular}

Fatigue characteristics of JJ1 and ST316LN were also evaluated to confirm the structural integrity of the magnet system under cyclic loads during plasma operations. The maximum stress cycle in the TF coil case occurs between Initial Magnetization (IM) and End of Burn (EOB) and between IM and Plasma Disruption (PD). The maximum stress amplitudes are estimated to be $398 \mathrm{MPa}$ on JJ1 and $160 \mathrm{MPa}$ on ST316 between IM-EOB with $3 \times 10^{4}$ cycles, and $539 \mathrm{MPa}$ on JJ1 and $384 \mathrm{MPa}$ on ST316 between IM-PD with $3 \times 10^{3}$ cycles. Stress vs number-to-failure (S-N) curves were measured on JJ1 and ST316LN at a range from $1 \times 10^{4}$ to $2 \times 10^{6}$ cycles. Measured results are shown in FIG. 10. From the measured data, a design S-N curve can be derived with safety factors of 2 for stress amplitude and 20 for cycles. As also shown in this figure, the design $\mathrm{S}-\mathrm{N}$ curves are well above the fatigue requirements for the coil case. As the next step of the development, trial machining and welding of the forged blocks and hot rolled plates into basic segments and sub-assemblies of the coil case will be performed. 


\section{Conclusions}

In Japan, the preparation for the ITER magnet system construction is now being performed in extensive collaboration with industries to provide a firm technical basis to realize the required performance of the magnets. Up to date, 1) advanced $\mathrm{Nb}_{3} \mathrm{Sn}$ strands has been developed, including CS and TF conductor jackets, 2) manufacturing studies on the TF coil winding and structures have been performed and 3) manufactures of structural materials at full scale have been performed. All of these results are satisfactory, although further technology development is required in some areas, as indicated in this paper.

\section{Acknowledgement}

The authors would like to thank Drs. M. Seki, T. Tsunematsu, S. Seki, R. Yoshino, H. Takatsu and M. Mori for their continuing supports on this work. The authors are also deeply grateful for significant contributions from Japanese industrial partners, including strand companies, cable companies, electric companies, steel companies and heavy industries companies.

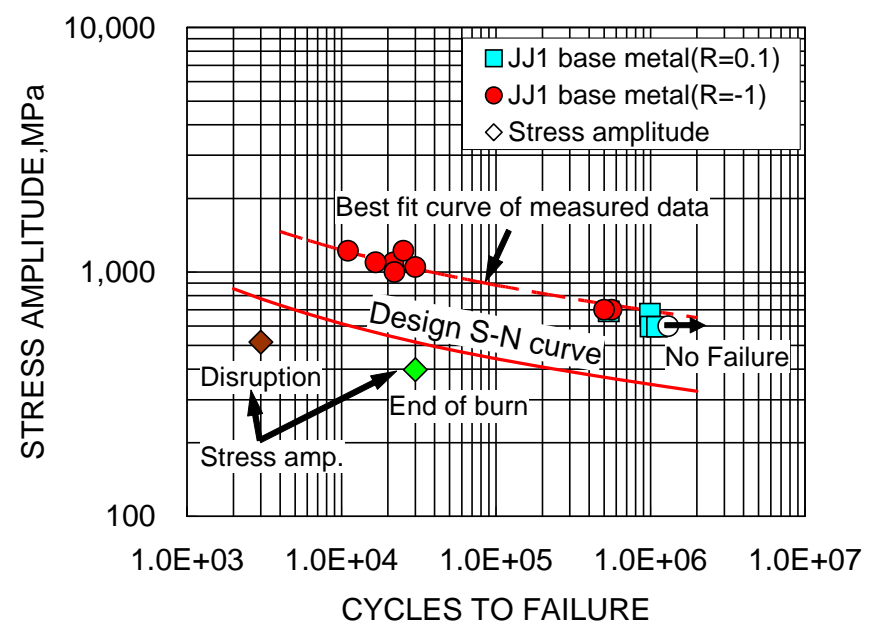

(a) JJ1 forging

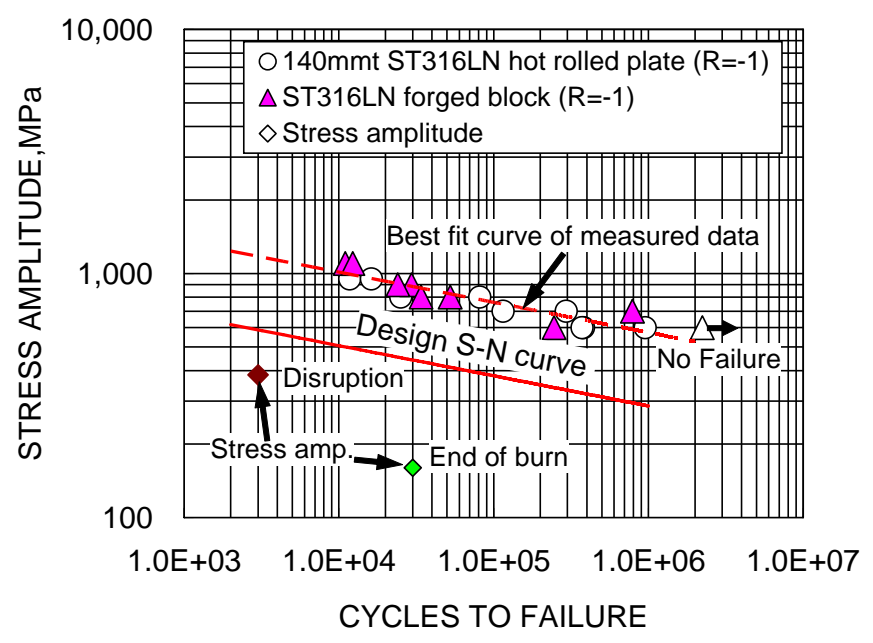

(b) ST316LN forging and hot rolled plate

FIG. 10. Fatigue characteristics of JJ1 and ST316LN.

\section{References}

[1] K. Okuno, et al., "Japanese contributions to the procurement of the ITER superconducting magnet”, Fusion Eng. Des. (in press).

[2] K. Okuno, et al., "From CS and TF Model Coils to ITER: Lessons Learnt and Further Progress", IEEE Trans on Appl. Supercond. Vol. 16 No.2 (2006) 850-885.

[3] N. Mitchell, "Summary, Assessment and Implications of the ITER Model Coils Test Results", Fusion Eng. Des. 66-68 (2003) 971-993.

[4] Y. Nunoya, et al., "Development of strain-applying apparatus for evaluation of ITER $\mathrm{Nb}_{3} \mathrm{Sn}$ strand", presented at Appl. Supercond. Conference, Seattle (2006).

[5] H. Nakajima, et al., "Development of low carbon and boron added 22Mn-13Cr-9Ni$1 \mathrm{Mo}-0.24 \mathrm{~N}$ steel (JK2LB) for jacket which undergoes $\mathrm{Nb}_{3} \mathrm{Sn}$ heat treatment", IEEE Trans on Appl. Supercond. Vol. 14, No.2 (2002) 1145-1148.

[6] H. Nakajima, et al., "Development of Optimum Manufacturing Technologies of Radial Plates for the ITER Toroidal Field Coils", presented at 24th Symposium on Fusion Technology, Warsaw (2006).

[7] K. Hamada, et al., "Demonstration of full scale JJ1 and 316LN fabrication for ITER TF coil structure", presented at 24th Symposium on Fusion Technology, Warsaw (2006). 